\title{
Nationwide epidemiological study revealed the dissemination of meticillin-resistant Staphylococcus aureus carrying a specific set of virulence-associated genes in Japanese hospitals
}

\begin{abstract}
Correspondence
Michio Ohta

mohta@med.nagoya-u.ac.jp
\end{abstract}

Received 9 February 2009

Accepted 22 May 2009

\author{
Teruko Ohkura, ${ }^{1}$ Keiko Yamada, ${ }^{1}$ Akira Okamoto, ${ }^{1}$ Hisashi Baba, ${ }^{2}$ \\ Yasuyoshi lke, ${ }^{3}$ Yoshichika Arakawa, ${ }^{4}$ Tadao Hasegawa ${ }^{5}$ and Michio Ohta ${ }^{1}$ \\ ${ }^{1}$ Department of Bacteriology, Nagoya University Graduate School of Medicine, Nagoya, Aichi, Japan \\ ${ }^{2}$ Department of Infectious Diseases, Nagoya University Hospital, Nagoya, Aichi, Japan \\ ${ }^{3}$ Department of Bacteriology and Bacterial Infection Control, Gunma University Graduate School of \\ Medicine, Maebashi, Gunma, Japan \\ ${ }^{4}$ Department of Bacterial Pathogenesis and Infection Control, National Institute of Infectious \\ Diseases, Musashimurayama, Tokyo, Japan \\ ${ }^{5}$ Department of Bacteriology, Nagoya City University, School of Medical Sciences, Nagoya, Aichi, \\ Japan
}

To study comprehensive toxin profiles and the chromosomal diversity of current Japanese hospital-associated meticillin-resistant Staphylococcus aureus (HA-MRSA) strains, we conducted PCR-based identification of 28 toxin genes, and staphylococcal cassette chromosome mec (SCCmec) typing and PFGE analysis of 208 MRSA strains isolated from 100 hospitals throughout Japan. Of the tested HA-MRSA strains, $80.3 \%$ were tst-positive. The most frequent toxin gene profile was characterized by the carriage of 13 genes, $t s t, s e c$, seg, sei, sel, sem, sen, seo, lukED, hla, hlb, hld and $h / g-2$. Ninety of the 208 strains had this profile, which was named pattern A. Among the 118 non-pattern A strains, 100 had similar toxin gene profiles, the concordance rates to pattern $A$ of which were more than $80 \%$. Consequently, $91.3 \%$ of the examined HA-MRSA strains carried similar toxin profiles, although PFGE patterns showed a wide variation. These strains belonged to SCCmec type II, agr II and coagulase type II. We concluded that, unlike MRSA from many other countries, most of the Japanese HA-MRSA strains belonged to, or were related to, a specific group carrying the set of 13 toxin genes, irrespective of chromosomal diversity. In addition, among the 13 toxin genes, the coexistence rates of tst, sec and sel, and those of seg, sei, sem, sen and seo, were higher than for the other toxin genes. High coexistence rates of $t s t, s e c$ and sel genes suggested the presence of the pathogenicity island SaPIn 1 in these strains.

\section{INTRODUCTION}

Meticillin-resistant Staphylococcus aureus (MRSA) still remains the most important hospital-associated pathogen in many countries. The rate of MRSA incidence among $S$. aureus isolates has been approximately $70 \%$ in most Japanese hospitals over the past 20 years (Kimura et al., 1992; Diekema et al., 2001). The exotoxin gene profiles of MRSA have been used as molecular epidemiological markers. Moreover, the profile of exotoxin genes in a strain can be a potential factor of the virulence aspect of the strain.

Abbreviations: HA-MRSA, hospital-associated MRSA; MLST, multilocus sequence typing; MRSA, meticillin-resistant Staphylococcus aureus; SCCmec, staphylococcal cassette chromosome mec.
Molecular epidemiological studies of MRSA have also been conducted by using methods such as PFGE, multilocus sequence typing (MLST) and staphylococcal cassette chromosome mec (SCCmec) typing. By using PFGE, Oliveira et al. (2002) identified five major MRSA clones. Among these clones, USA100 (New York/Japan) was characterized as a clonal complex 5:ST5-MRSA-II by MLST and SCCmec typing (Enright et al., 2002; McDougal et al., 2003). The USA100 clone includes the largest group of isolates from throughout the United States (McDougal et al., 2003). These were characterized as enterotoxin gene cluster (egc) locus-positive and tst-negative (Diep et al., 2006), whereas previous studies suggested that Japanese MRSA isolates which were supposed to belong to the 
USA100 clone (New York/Japan clone) were tst-positive and egc locus-positive (Piao et al., 2005; Zaraket et al., 2007; Nishi et al., 2002; Hu et al., 2008), although strains from only a limited area were analysed in these studies. MLST- and PFGE-based epidemiological classification therefore is likely insufficient for the characterization of isolates regarding their virulence aspects. An investigation of toxin profiles would provide fundamental information about the possible virulence of MRSA strains. The toxin gene profiles of Japanese MRSA isolates determined in the previous studies were based on local, not nationwide, surveillance. Therefore, the results of these studies did not necessarily represent the overall toxin characteristics of Japanese MRSA isolates.

In this study, we investigated the genotypic characteristics using a PCR method with reference to 28 virulenceassociated exotoxin genes and carried out chromosomal PFGE analysis of MRSA strains which were uniformly collected from hospitals located throughout Japan.

\section{METHODS}

Bacterial isolates. Two hundred and eight Japanese MRSA strains were analysed in this study. These strains were randomly collected from 100 different hospitals located throughout Japan during 20022004 by a nationwide surveillance study conducted by the National Institute of Infectious Diseases, Japan. In order to investigate the general features of the toxin gene carriage of Japanese MRSA strains, the 100 hospitals were selected to cover as much as possible of the area of Japan (Fig. 1). In addition, only one to four strains were collected from each hospital. Further, these strains were isolated from various clinical specimens from epidemiologically unrelated patients, which included carriers and infected patients. The specimens included blood $(n=34)$, intracatheter $(n=2)$, sputum $(n=78)$, tracheal tube $(n=1)$, pharyngeal mucosa $(n=16)$, nasal mucosa $(n=13)$, faeces $(n=10)$, urine $(n=4)$, otorrhoea $(n=10)$, skin $(n=3)$, pus $(n=28)$, soft tissue $(n=1)$, cerebrospinal fluid $(n=1)$, pleural effusion $(n=1)$, ascites $(n=1)$, vaginal discharge $(n=1)$ and others $(n=4)$.

The strains were identified as MRSA in each hospital. In our laboratory, all collected strains were reconfirmed as MRSA by conventional biological tests and by the presence of the mecA gene using PCR with specific primers (Bignardi et al., 1996).

Template preparation and PCR procedure. Template DNA of $S$. aureus was prepared as described previously (Louie et al., 2000). Primers that were previously described for the $t s t$, sea, seb, sec, sed, see, seg, seh, sei, sej, sem, sen, seo, edinA, lukPV, lukED, lukM, hla, hlb, hld, $h l g$ and $h l g-2$ genes were used (Jarraud et al., 2002). Primers for other genes were designed in this study from the sequences deposited in GenBank (NCBI) as shown in Table 1. Strains used for positive controls are listed in Table 2. The presence of the toxin genes in these positive controls of clinical origin was confirmed by PCR followed by DNA sequencing, and, when necessary, gene products were identified by proteomic analysis (Nakano et al., 2002a).

PCR was performed in a $10 \mu \mathrm{l}$ reaction mixture containing $0.4 \mu \mathrm{l}$ template DNA, $1 \mu \mathrm{l} 10 \times$ Taq buffer, $0.8 \mu \mathrm{ldNTP}$ mixture, $0.5 \mu \mathrm{M}$ of each primer and $0.25 \mathrm{U}$ Taq polymerase (Takara Bio). The following amplification cycles were repeated 30 times: denaturation for $30 \mathrm{~s}$ at $94{ }^{\circ} \mathrm{C}$, annealing of primers for $30 \mathrm{~s}$ at suitable temperature for each amplification, and extension for $60 \mathrm{~s}$ at $72{ }^{\circ} \mathrm{C}$. Amplified products were analysed by $1.4 \%$ agarose gel electrophoresis in $1 \times$ TAE buffer at $135 \mathrm{~V}$ for $20 \mathrm{~min}$. The gel was stained with ethidium bromide and

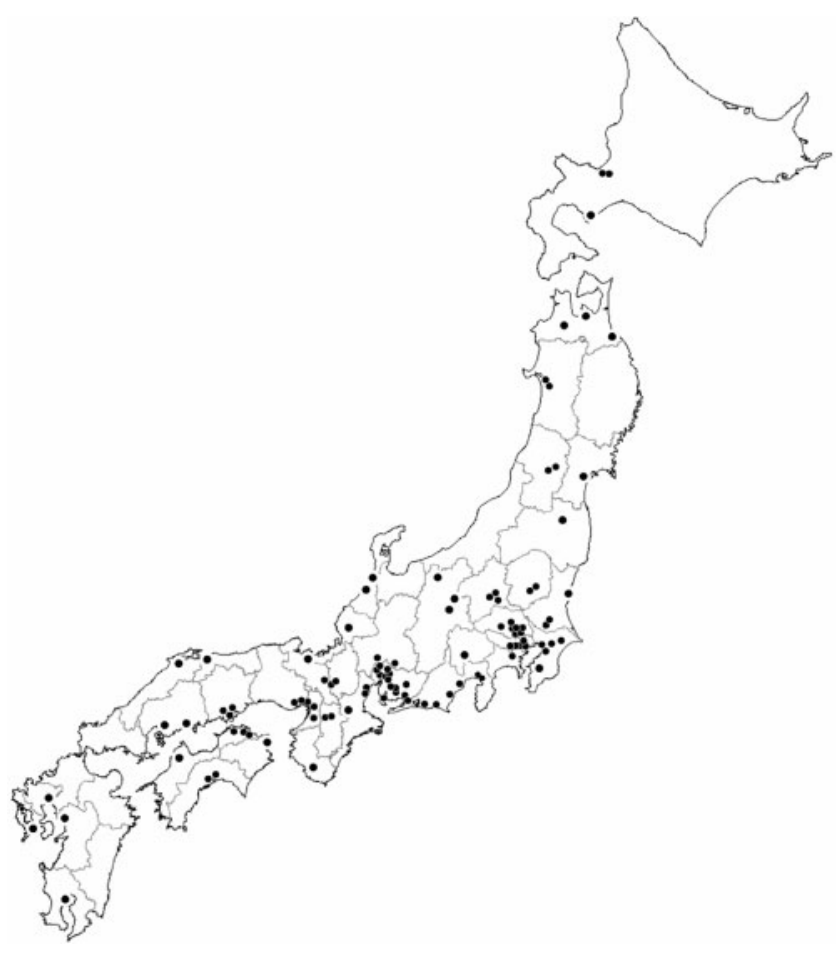

Fig. 1. Distribution map of 100 Japanese hospitals. Filled circles represent the locations of hospitals where the 208 MRSA strains were isolated.

then exposed to UV light to visualize the amplified products. When the bands were not clear, we repeated the experiment a few times to confirm the reproducibility.

Typing of SCCmec, agr and coagulase. SCCmec typing was performed by PCR using previously published primers that identified the class of mec gene complex and the type of cassette chromosome recombinase (ccr) gene (Ito et al., 2001). The agr class was determined by PCR using specific primers as previously described (Gilot et al., 2002). Coagulase typing was performed with a staphylococcal coagulase typing antiserum kit (Denka Seiken).

Chromosomal DNA fingerprinting by PFGE. SmaI macrorestriction patterns of chromosomal DNA were obtained by use of the CHEF-DR III System (Bio-Rad) with the following settings: voltage, $6 \mathrm{~V} \mathrm{~cm}^{-1}$; temperature, $14{ }^{\circ} \mathrm{C}$; initial time, $1 \mathrm{~s}$; final time, $40 \mathrm{~s}$; and duration, $20 \mathrm{~h}$. Chromosomal patterns were examined visually, and digitally analysed with Finger Print II (Bio-Rad) to generate a dendrogram based on Dice coefficients. PFGE patterns were grouped according to the criterion of Tenover et al. (1995) and using a dendrogram similarity of more than $80 \%$ to assign strain relatedness (McDougal et al., 2003).

\section{RESULTS AND DISCUSSION}

\section{Carriage profile of superantigenic toxin genes in Japanese hospital-associated MRSA (HA-MRSA)}

The toxin genes were detected with the aforementioned published primers and the primers that we newly designed 
Table 1. Primers newly designed in this study

\begin{tabular}{|c|c|c|c|c|}
\hline Gene & Primer & Sequence $\left(5^{\prime}-3^{\prime}\right)$ & $\begin{array}{l}\text { Annealing temperature } \\
\qquad\left({ }^{\circ} \mathrm{C}\right)\end{array}$ & $\begin{array}{c}\text { Product } \\
\text { length }(b p)\end{array}$ \\
\hline \multirow[t]{2}{*}{ sek } & sek-f & AACTTGATGTTTTTGGTATT & 56.0 & 237 \\
\hline & sek-r & AAATGTTGTATTCTTCTTGA & & \\
\hline \multirow[t]{2}{*}{ sel } & sel-f & TGATACATTGTATGCTGAAT & 56.0 & 427 \\
\hline & sel-r & GTAAAATAAATCATACGTGT & & \\
\hline \multirow[t]{2}{*}{ eta } & eta- $\mathrm{f}$ & CTATTTACTGTAGGAGCTAG & 47.5 & 741 \\
\hline & eta-r & ATTTATTTGATGCTCTCTAT & & \\
\hline \multirow[t]{2}{*}{$e t b$} & $e t b-\mathrm{f}$ & ATACACACATTACGGATAAT & 50.5 & 629 \\
\hline & $e t b-\mathrm{r}$ & CAAAGTGTCTCCAAAAGTAT & & \\
\hline \multirow[t]{2}{*}{$e d i n B$} & $\operatorname{edin} B-\mathrm{f}$ & CATAAATACTCCTCTAAG & 54.0 & 444 \\
\hline & edinB-r & GCATATTCTGTCCСТCTA & & \\
\hline \multirow[t]{2}{*}{ edinC } & $\operatorname{edin} C-\mathrm{f}$ & TATTAAGCATTCATTCAA & 44.0 & 626 \\
\hline & edin $C-\mathrm{r}$ & GTAGTCTGTTCCTCTA & & \\
\hline
\end{tabular}

in this study based on the DNA sequence databases. As shown in Table 3, the positive carriage rates of $t s t$, sec, seg, sei, sel, sem, sen and seo were 76.4-94.2\%. The carriage rates of these eight genes were much higher than those of sea $(9.6 \%)$ and seb $(21.2 \%)$. The other superantigenic toxin genes, sed, see, seh, sej and sek, showed low carriage rates of less than $2.4 \%$. Two hundred and four out of 208 strains carried at least one of the 15 superantigenic toxin genes tested in this study, which corresponds to a carriage rate of $98.1 \%$.

\section{Carriage profile of other toxin genes}

The exfoliative toxin genes eta and $e t b$ and the epidermal cell differentiation inhibitor genes edinA, edinB and edinC were rarely detected. Only two strains were eta-positive. These two strains carried none of the superantigenic toxin genes. Panton-Valentine leukocidin component genes lukPV were not detected in any of the strains. The lukED genes showed a high carriage rate of $96.6 \%$. Haemolysin genes $h l a, h l b$, hld and $h l g-2$ variant were also frequently detected. The $\gamma$-haemolysin gene variant $h l g$ - 2 was dominant in Japanese MRSA strains.

\section{Toxin patterns of HA-MRSA}

Fifty-eight different toxin patterns were identified in the 208 HA-MRSA strains. The major patterns are shown in Table 4. The most frequent pattern, pattern $A$, was characterized by the carriage of the following 13 genes: tst, sec, seg, sei, sel, sem, sen, seo, lukED, hla, hlb, hld and hlg2. Ninety strains showed this pattern, which corresponds to $43.3 \%$ of all tested strains. The next most frequent major patterns were patterns B, C, and D. Only one out of 28 genes was different in these three patterns compared to pattern A. Therefore, these patterns showed high concordance rates of $96.4 \%$ to pattern A. The minor toxin patterns also showed high concordance rates. One hundred strains had concordance rates of more than $82.1 \%$ to pattern $\mathrm{A}$, which corresponds to $84.7 \%$ of the MRSA strains other than of pattern A; i.e. 190 strains $(91.3 \%)$ carried quite similar toxin profiles.

Table 2. Strains used for positive controls

\begin{tabular}{|c|c|c|}
\hline Strain & Gene & Source \\
\hline MRSA N315 & $\begin{array}{l}\text { tst, sec, seg, sei, sel, sem, sen, seo, } \\
\text { lukED, hla, hlb, hld, hlg- } 2\end{array}$ & Kuroda et al. (2001) \\
\hline S. aureus ATCC 27664 & see & Sergeev et al. (2004) \\
\hline S. aureus ATCC 49775 & $l u k P V, h l g$ & Lina et al. (1999) \\
\hline S. aureus ATCC 31890 & lukM & Kaneko et al. (1997) \\
\hline MRSA MF330 & sea, seb, seh, sek & Clinical isolate ${ }^{\star}$ \\
\hline MRSA GG28 & sed, sej & Clinical isolate ${ }^{\star}$ \\
\hline MRSA MH & eta & Clinical isolate $\dagger$ \\
\hline MRSA NA1 & $e t b, e d i n C$ & Clinical isolate $\dagger$ \\
\hline MRSA C9 & edinA & Clinical isolate \\
\hline MRSA B11 & $\operatorname{edin} B$ & Clinical isolate $\ddagger$ \\
\hline
\end{tabular}

${ }^{\star}$ Food poisoning.

$\dagger$ Staphylococcal scalded skin syndrome.

$\ddagger$ Skin region of atopic dermatitis. 


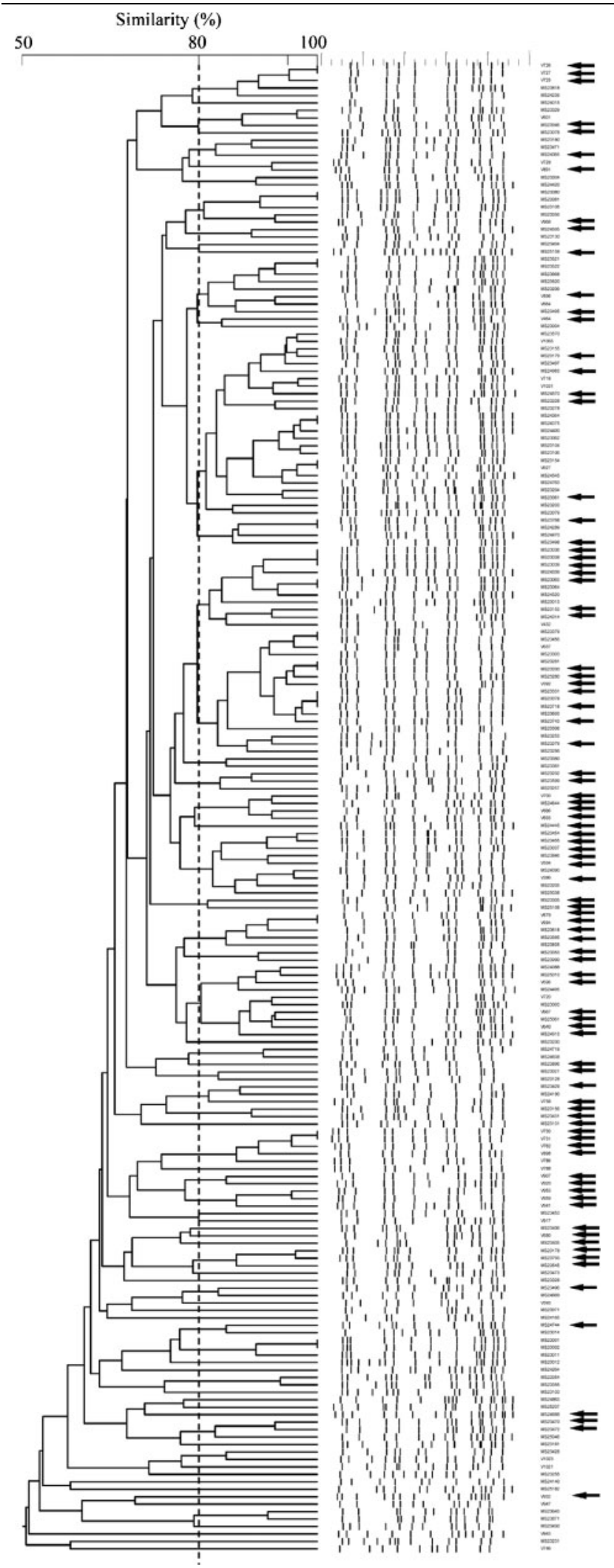

Fig. 2. Dendrogram of PFGE results based on the Dice coefficients and schematic representation of the Smal restriction pulsotype of Japanese MRSA strains. Arrows represent strains belonging to the most frequent toxin gene pattern $A$ group. Strain names are available from the corresponding author.
Table 3. Identification of toxin genes in Japanese MRSA strains

\begin{tabular}{|c|c|c|c|}
\hline \multirow[t]{2}{*}{ Pathogenic factor } & \multirow[t]{2}{*}{ Gene } & \multicolumn{2}{|c|}{$\begin{array}{c}\text { MRSA } \\
(n=208)\end{array}$} \\
\hline & & $n$ & $\%$ \\
\hline Toxic shock syndrome toxin 1 & tst & 167 & 80.3 \\
\hline \multirow[t]{14}{*}{ Enterotoxins } & sea & 20 & 9.6 \\
\hline & seb & 44 & 21.2 \\
\hline & $\sec$ & 168 & 80.8 \\
\hline & sed & 2 & 1.0 \\
\hline & see & 0 & 0.0 \\
\hline & $\operatorname{seg}$ & 186 & 89.4 \\
\hline & seh & 3 & 1.4 \\
\hline & sei & 189 & 90.9 \\
\hline & $\operatorname{sej}$ & 3 & 1.4 \\
\hline & sek & 5 & 2.4 \\
\hline & sel & 159 & 76.4 \\
\hline & sem & 196 & 94.2 \\
\hline & $\operatorname{sen}$ & 184 & 88.5 \\
\hline & seo & 195 & 93.8 \\
\hline More than one of the superantigens & & 204 & 98.1 \\
\hline \multirow[t]{2}{*}{ Exfoliative toxins } & eta & 2 & 1.0 \\
\hline & $e t b$ & 0 & 0.0 \\
\hline \multirow{3}{*}{$\begin{array}{l}\text { Epidermal cell differentiation } \\
\text { inhibitors }\end{array}$} & $\operatorname{edin} A$ & 0 & 0.0 \\
\hline & $e \operatorname{din} B$ & 0 & 0.0 \\
\hline & $\operatorname{edin} C$ & 0 & 0.0 \\
\hline \multirow[t]{3}{*}{ Leukocidins } & $l u k P V$ & 0 & 0.0 \\
\hline & $l u k E D$ & 201 & 96.6 \\
\hline & $l u k M$ & 0 & 0.0 \\
\hline \multirow[t]{5}{*}{ Haemolysins } & hla & 202 & 97.1 \\
\hline & $h l b$ & 176 & 84.6 \\
\hline & hld & 203 & 97.6 \\
\hline & hlg & 4 & 1.9 \\
\hline & hlg-2 & 202 & 97.1 \\
\hline
\end{tabular}

\section{SCCmec type, agr class and coagulase type of strains with major toxin patterns}

The types of SCCmec, agr and coagulase were determined for ten strains with major toxin patterns which were selected randomly. Of ten strains, three were from toxin pattern $A$, two from pattern $B$, two from pattern $C$, one from pattern $D$, one from pattern $\mathrm{E}$, and one from pattern $\mathrm{F}$. We found that all strains were SCCmec type II, agr class II and coagulase type II. Irrespective of differences in toxin pattern, these strains belonged to a single group of SCCmec, agr and coagulase types. The SCCmec region and most of the toxin genes analysed in this study were supposed to be extrinsic in origin (Kuroda et al., 2001; Novick, 2003). It is therefore likely that the acquisition of the SCCmec region and the toxin genes were genetically independent events.

\section{PFGE profiles}

PFGE typing was performed for all of the 208 HA-MRSA strains. Of these, 202 were successfully analysed (Fig. 2). 
Table 4. Major patterns among the 58 toxin patterns in Japanese MRSA strains

+ , Gene is present; blank cells, gene is absent.

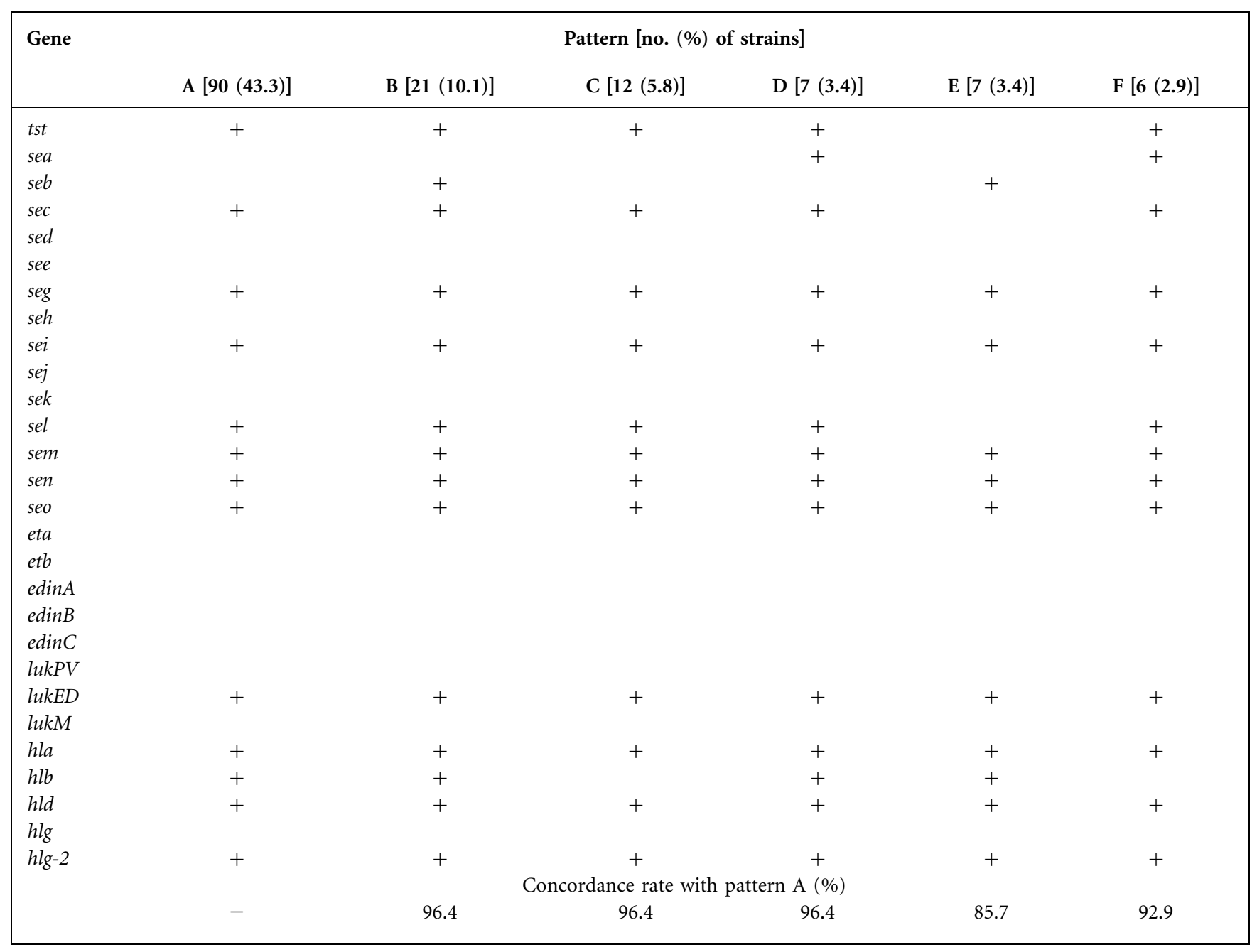

The PFGE profiles of the 202 strains were classified into 74 PFGE types using a cut-off of $80 \%$ similarity (McDougal et al., 2003) as well as the criterion of Tenover et al. (1995). Among the 202 strains, 89 shown with arrows in Fig. 2 belonged to the toxin gene pattern A group and these strains were classified into 39 PFGE types, corresponding to $52.7 \%$ of all the identified PFGE types. This indicated that the strains carrying the set of pattern A toxin genes differentiated without changing stable carriage of these toxin genes or rather that extrinsic genetic elements such as phages and plasmids which carried the toxin genes were disseminated by horizontal transmission among various HA-MRSA strains in Japan.

In a previous study, Piao et al. (2005) determined toxin patterns of Japanese MRSA isolated from a hospital in Tokyo. Similar studies were also conducted in other hospitals (Zaraket et al., 2007; Nishi et al., 2002; $\mathrm{Hu}$ et al., 2008). These four studies commonly reported the high carriage rate of tst, sec and the egc locus (seg, sei, sem, sen and seo), although MRSA strains for the analysis in each study were collected from hospitals within a narrow geographical area. Our study also presented similar but more conclusive results for strains collected throughout Japan. The toxin patterns that we have determined therefore could represent those of MRSA isolates from throughout Japan having various genetic backgrounds as determined by PFGE.

\section{Coexistence of toxin genes}

As shown in Table 4, while most of the major patterns had high concordance rates with pattern $A$, pattern $E$ showed somewhat lower concordance. This was due to a lack of tst, sec and sel genes. We also observed the same for the minor toxin patterns, which are not shown in Table 4. Regardless of whether they were major or minor, the toxin patterns showing relatively lower concordance rates often lacked $t s t$, sec and sel genes at the same time. Similarly, there were some strains which lacked a set of seg, sei, sem, sen and seo genes. In order to evaluate the coexistence of toxin genes 


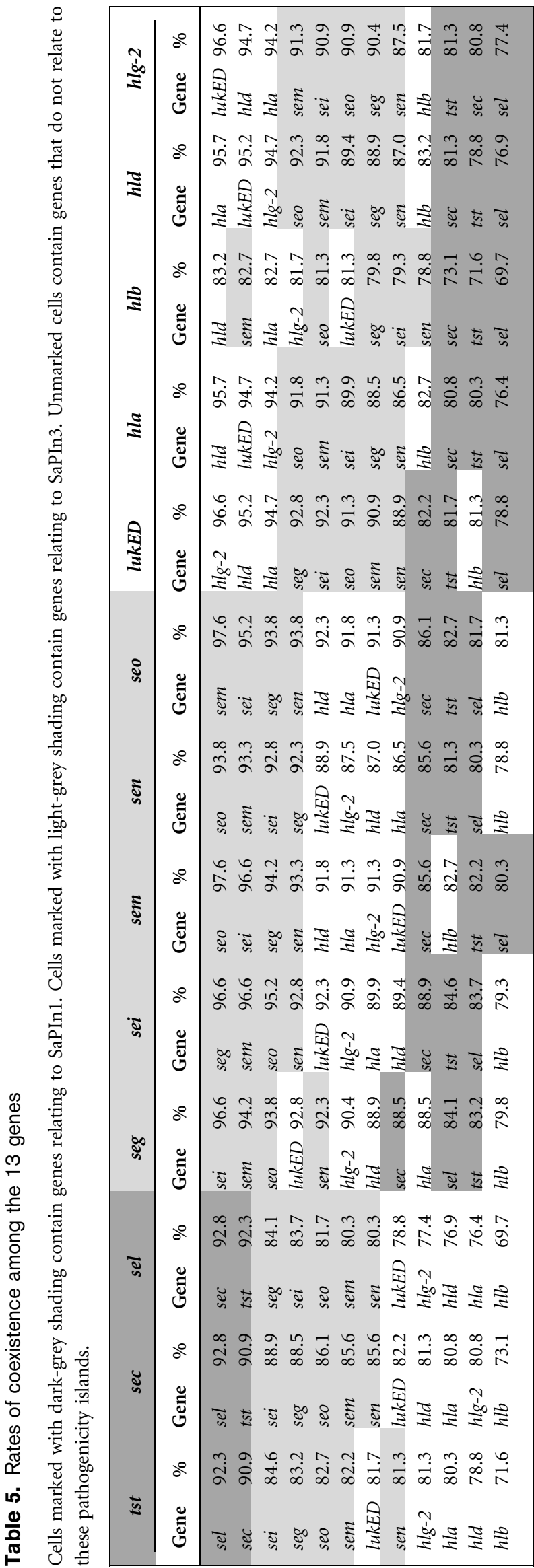

quantitatively, we calculated the coexistence rates between 13 genes in each strain (Table 5). The 13 genes were $t s t, s e c$, seg, sei, sel, sem, sen, seo, lukED, hla, hlb, hld and hlg-2, which belonged to pattern A. As already mentioned above, these 13 genes showed high carriage rates among the examined strains, resulting in high coexistence rates with each other. However, as shown in Table 5, if we arrange them in order of the coexistence rate, tst, sec, sel genes showed the highest coexistence rates between each other (marked with dark grey). Likewise, seg, sei, sem, sen and seo genes showed higher coexistence rates (marked with light grey). Consequently, our results indicate that the set of three genes tst, sec and sel, and the set of five genes seg, sei, sem, sen and seo, highly coexist in Japanese HAMRSA. According to the genome analysis of an early Japanese hospital isolate, MRSA N315, two major pathogenicity islands, SaPIn1 and SaPIn3, were identified on the chromosome (Kuroda et al., 2001). SaPIn1 was characterized as the carrier of $t s t$, sec and sel genes and SaPIn3 was the carrier of the egc locus and lukED genes. In the egc locus of N315, seg, sei, sem, sen and seo genes were identified. In our study, we confirmed that the toxin pattern of MRSA N315 belongs to the most frequent pattern A. In addition, our results showed that the correlation of existence between tst, sec and sel, and also between seg, sei, sem, sen and seo, was higher than for the other toxin genes, which suggested that a majority of Japanese HA-MRSA strains probably carried pathogenicity islands SaPIn1 and SaPIn3.

\section{Characterization of Japanese MRSA isolates regarding their virulence aspects}

The pathogenicity of MRSA depends, at least partially, on the toxin repertoire of each MRSA strain. Therefore, the manifestations of MRSA infection may vary in different countries. The most remarkable difference between the toxin patterns of Japanese strains and those of MRSA strains isolated in European countries and North America was high carriage and high coexistence rates of tst, sec and sel genes in the Japanese strains. These three genes have been rarely observed in European and North American MRSA strains. We reported in a previous study that MRSA strains isolated from patients with neonatal toxic shock syndrome-like exanthematous disease (NTED) produced a large amount of TSST-1 and SEC (Nakano et al., 2002b). Moreover, MRSA strains associated with enterocolitis, which was sometimes accompanied by toxic shock syndrome and multiorgan failure, were also TSST-1- and SEC-positive (Watanabe et al., 2001). The patients with NTED have been reported only in Japan (Takahashi et al., 1998; Takahashi, 2003). MRSA-associated enterocolitis has been occasionally observed in Japanese patients receiving surgical operations, while it has rarely been reported in other countries. It is therefore likely that Japanese MRSA isolates that were tst- and sec-positive were involved in the aetiology of these infections. As for the Japanese HAMRSA strains, most of the $S$. aureus isolates from 
European countries also carried an identical egc locus (Jarraud et al., 2001). The typical egc locus encodes five intact enterotoxins, for which superantigenic activities have been proven (Jarraud et al., 2001). These enterotoxins, however, are unlikely to be involved in the pathogenesis of severe infections, since their expression level is very low (Omoe et al., 2002) and, moreover, the prevalence of the egc locus in S. aureus decreases significantly with severity of infection (Ferry et al., 2005).

The conclusive result in our study was that the most of the Japanese HA-MRSA isolates had specific toxin patterns which were characterized by a high carriage rate of $t s t, s e c$, seg, sei, sel, sem, sen, seo, lukED, hla, hlb, hld and hlg-2 genes, although their PFGE patterns showed a wide variation. Compared with strains isolated in European countries and North America, the most remarkable difference was that Japanese MRSA isolates carried $t s t$, sec and sel genes at high frequencies.

\section{ACKNOWLEDGEMENTS}

This work was supported by Grants-in-Aid (No. 12557027 and 14370090) for Scientific Research from the Ministry of Education, Science, Sports, and Culture, Japan.

\section{REFERENCES}

Bignardi, G. E., Woodford, N., Chapman, A., Johnson, A. P. \& Speller, D. C. (1996). Detection of the mec-A gene and phenotypic detection of resistance in Staphylococcus aureus isolates with borderline or lowlevel methicillin resistance. J Antimicrob Chemother 37, 53-63.

Diekema, D. J., Pfaller, M. A., Schmitz, F. J., Smayevsky, J., Bell, J., Jones, R. N., Beach, M. \& SENTRY Participants Group (2001). Survey of infections due to Staphylococcus species: frequency of occurrence and antimicrobial susceptibility of isolates collected in the United States, Canada, Latin America, Europe, and the Western Pacific region for the SENTRY Antimicrobial Surveillance Program, 1997-1999. Clin Infect Dis 32, S114-S132.

Diep, B. A., Carleton, H. A., Chang, R. F., Sensabaugh, G. F. \& Perdreau-Remington, F. (2006). Roles of 34 virulence genes in the evolution of hospital- and community-associated strains of methicillin-resistant Staphylococcus aureus. J Infect Dis 193, 1495-1503.

Enright, M. C., Robinson, D. A., Randle, G., Feil, E. J., Grundmann, H. \& Spratt, B. G. (2002). The evolutionary history of methicillinresistant Staphylococcus aureus (MRSA). Proc Natl Acad Sci U S A 99, 7687-7692.

Ferry, T., Thomas, D., Genestier, A. L., Bes, M., Lina, G., Vandenesch, F. \& Etienne, J. (2005). Comparative prevalence of superantigen genes in Staphylococcus aureus isolates causing sepsis with and without septic shock. Clin Infect Dis 41, 771-777.

Gilot, P., Lina, G., Cochard, T. \& Poutrel, B. (2002). Analysis of the genetic variability of genes encoding the RNA III-activating components Agric and TRAP in a population of Staphylococcus aureus strains isolated from cows with mastitis. J Clin Microbiol 40, 4060-4067.

Hu, D. L., Omoe, K., Inoue, F., Kasai, T., Yasujima, M., Shinagawa, K. \& Nakane, A. (2008). Comparative prevalence of superantigenic toxin genes in meticillin-resistant and meticillin-susceptible Staphylococcus aureus isolates. J Med Microbiol 57, 1106-1112.
Ito, T., Katayama, Y., Asada, K., Mori, N., Tsutsumimoto, K., Tiensasitorn, C. \& Hiramatsu, K. (2001). Structural comparison of three types of staphylococcal cassette chromosome mec integrated in the chromosome in methicillin-resistant Staphylococcus aureus. Antimicrob Agents Chemother 45, 1323-1336.

Jarraud, S., Peyrat, M. A., Lim, A., Tristan, A., Bes, M., Mougel, C., Etienne, J., Vandenesch, F., Bonneville, M. \& Lina, G. (2001). egc, a highly prevalent operon of enterotoxin gene, forms a putative nursery of superantigens in Staphylococcus aureus. J Immunol 166, 669-677.

Jarraud, S., Mougel, C., Thioulouse, J., Lina, G., Meugnier, H., Forey, F., Nesme, X., Etienne, J. \& Vandenesch, F. (2002). Relationships between Staphylococcus aureus genetic background, virulence factors, agr groups (alleles), and human disease. Infect Immun 70, 631-641.

Kaneko, J., Muramoto, K. \& Kamio, Y. (1997). Gene of LukF-PV-like component of Panton-Valentine leukocidin in Staphylococcus aureus P83 is linked with lukM. Biosci Biotechnol Biochem 61, 541-544.

Kimura, A., Igarashi, H., Ushioda, H., Okuzumi, K., Kobayashi, H. \& Otsuka, T. (1992). Epidemiological study of Staphylococcus aureus isolated from the Japanese national university and medical college hospitals with coagulase typing, and production of enterotoxins and toxic shock syndrome toxin-1. Kansenshogaku Zasshi 66, 1543-1549.

Kuroda, M., Ohta, T., Uchiyama, I., Baba, T., Yuzawa, H., Kobayashi, I., Cui, L., Oguchi, A., Aoki, K. \& other authors (2001). Whole genome sequencing of meticillin-resistant Staphylococcus aureus. Lancet 357, $1225-1240$.

Lina, G., Piémont, Y., Godail-Gamot, F., Bes, M., Peter, M. O., Gauduchon, V., Vandenesch, F. \& Etienne, J. (1999). Involvement of Panton-Valentine leukocidin-producing Staphylococcus aureus in primary skin infections and pneumonia. Clin Infect Dis 29, 11281132.

Louie, L., Matsumura, S. O., Choi, E., Louie, M. \& Simor, A. E. (2000). Evaluation of three rapid methods for detection of methicillin resistance in Staphylococcus aureus. J Clin Microbiol 38, 2170-2173.

McDougal, L. K., Steward, C. D., Killgore, G. E., Chaitram, J. M., McAllister, S. K. \& Tenover, F. C. (2003). Pulsed-field gel electrophoresis typing of oxacillin-resistant Staphylococcus aureus isolates from the United States: establishing a national database. J Clin Microbiol 41, 5113-5120.

Nakano, M., Kawano, Y., Kawagishi, M., Hasegawa, T., linuma, Y. \& Ohta, M. (2002a). Two-dimensional analysis of exoproteins of methicillin-resistant Staphylococcus aureus (MRSA) for possible epidemiological applications. Microbiol Immunol 46, 11-22.

Nakano, M., Miyazawa, H., Kawano, Y., Kawagishi, M., Torii, K., Hasegawa, T., linuma, Y. \& Ohta, M. (2002b). An outbreak of neonatal toxic shock syndrome-like exanthematous disease (NTED) caused by methicillin-resistant Staphylococcus aureus (MRSA) in a neonatal intensive care unit. Microbiol Immunol 46, 277-284.

Nishi, J., Yoshinaga, M., Miyanohara, H., Kawahara, M., Kawabata, M., Motoya, T., Owaki, T., Oiso, S., Kawakami, M. \& other authors (2002). An epidemiological survey of methicillin-resistant Staphylococcus aureus by combined use of mec-HVR genotyping and toxin genotyping in a university hospital in Japan. Infect Control Hosp Epidemiol 23, 506-510.

Novick, R. P. (2003). Mobile genetic elements and bacterial toxinoses: the superantigen-encoding pathogenicity islands of Staphylococcus aureus. Plasmid 49, 93-105.

Oliveira, D. C., Tomasz, A. \& De Lencastre, H. (2002). Secrets of success of a human pathogen: molecular evolution of pandemic clones of meticillin-resistant Staphylococcus aureus. Lancet Infect Dis 2, 180-189.

Omoe, K., Ishikawa, M., Shimoda, Y., Hu, D. L., Ueda, S. \& Shinagawa, K. (2002). Detection of seg, seh, and sei genes in 
Staphylococcus aureus isolates and determination of the enterotoxin productivities of $S$. aureus isolates harboring seg, seh, or sei genes. J Clin Microbiol 40, 857-862.

Piao, C., Karasawa, T., Totsuka, K., Uchiyama, T. \& Kikuchi, K. (2005). Prospective surveillance of community-onset and healthcare-associated methicillin-resistant Staphylococcus aureus isolated from a universityaffiliated hospital in Japan. Microbiol Immunol 49, 959-970.

Sergeev, N., Volokhov, D., Chizhikov, V. \& Rasooly, A. (2004). Simultaneous analysis of multiple staphylococcal enterotoxin genes by an oligonucleotide microarray assay. J Clin Microbiol 42, 2134-2143.

Takahashi, N. (2003). Neonatal toxic shock syndrome-like exanthematous disease (NTED). Pediatr Int 45, 233-237.

Takahashi, N., Nishida, H., Kato, H., Imanishi, K., Sakata, Y. \& Uchiyama, T. (1998). Exanthematous disease induced by toxic shock syndrome toxin 1 in the early neonatal period. Lancet 351, 1614-1619.
Tenover, F. C., Arbeit, R. D., Goering, R. V., Mickelsen, P. A., Murray, B. E., Persing, D. H. \& Swaminathan, B. (1995). Interpreting chromosomal DNA restriction patterns produced by pulsed-field gel electrophoresis: criteria for bacterial strain typing. J Clin Microbiol 33, 2233-2239.

Watanabe, H., Masaki, H., Asoh, N., Watanabe, K., Oishi, K., Kobayashi, S., Sato, A. \& Nagatake, T. (2001). Enterocolitis caused by methicillin-resistant Staphylococcus aureus: molecular characterization of respiratory and digestive tract isolates. Microbiol Immunol 45, 629-634.

Zaraket, H., Otsuka, T., Saito, K., Dohmae, S., Takano, T., Higuchi, W., Ohkubo, T., Ozaki, K., Takano, M. \& other authors (2007). Molecular characterization of methicillin-resistant Staphylococcus aureus in hospitals in Niigata, Japan: divergence and transmission. Microbiol Immunol 51, 171-176. 